\title{
Evaluation of Patients with Ischemic Stroke Receiving iv t-PA in the Emergency Department
}

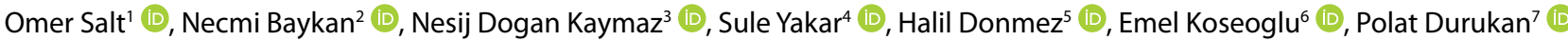 \\ 'Department of Emergency Medicine, Trakya University School of Medicine, Edirne, Turkey \\ ${ }^{2}$ Department of Emergency Medicine, Nevsehir State Hospital, Nevsehir, Turkey \\ ${ }^{3}$ Department of Emergency Medicine, Sultan 1. Murat State Hospital, Edirne, Turkey \\ ${ }^{4}$ Department of Emergency Medicine, Unye State Hospital, Ordu, Turkey \\ ${ }^{5}$ Department of Radiology, Erciyes University School of Medicine, Kayseri, Turkey \\ ${ }^{6}$ Department of Neurology, Erciyes University School of Medicine, Kayseri, Turkey \\ ${ }^{7}$ Department of Emergency Medicine, Erciyes University School of Medicine, Kayseri, Turkey
}

Cite this article as: Salt O, Baykan N, Kaymaz ND, Yakar S, Donmez S, Donmez H, et al. Evaluation of Patients with Ischemic Stroke Receiving iv t-PA in the Emergency Department. Eurasian J Emerg Med. 2018; 17: 50-4.

\begin{abstract}
Aim: The aim of the present study was to determine the demographic characteristics, localization of emboli, imaging findings, National Institutes of Health Stroke Scale (NIHSS) scores, and complications of patients who received intravenous (iv) tissue plasminogen activator (t-PA) due to early period of ischemic cerebrovascular disease (CVD) during the 6-year period in a tertiary level emergency department of a university hospital.

Materials and Methods: The study was retrospectively performed in 65 patients aged $\geq 18$ years and who underwent iv t-PA with a diagnosis of ischemic CVD. Demographic data, such as age, gender, and smoking, were obtained by examining the medical records of the patients. The baseline Glasgow Coma Scale, NIHSS, start time of the event, time of admission to the hospital, and prognosis of the patients were recorded.

Results: Intracranial hemorrhage was detected in $16.9 \%$ of the patients after treatment. On examination of the patients' outcome, a total of $32.3 \%$ ( $n=21$ ) died after therapy. A significant correlation was observed between high NIHSS score and complications.

Conclusion: In our study, a high NIHSS score at the time of admission has been found to increase both the risk of intracerebral hemorrhagic complication and mortality. We hypothesize that iv t-PA treatment gives successful results despite the complications, and emergency physicians should be more courageous in their application.
\end{abstract}

Keywords: Emergency medicine, ischemic stroke, tissue plasminogen activator

\section{Introduction}

Cerebrovascular disease (CVD) is a syndrome that occurs with the sudden deterioration of blood flow in the blood vessels of the brain (1). Thromboembolic events or occlusions result in ischemic strokes and constitute approximately $70 \%-80 \%$ of total stroke cases (2). It is the second most common cause of death worldwide, followed by cardiovascular diseases in the 60 years or older population. In addition, it is the major cause of disability and labor loss $(3,4)$. In Turkey, cardiovascular diseases are the leading cause of death with a rate of $21.7 \%$ and CVDs in second place with $15 \%(5)$.

Thrombolytic therapy with tissue plasminogen activator (t-PA) gives clinically much better results than other treatment options in

ORCID IDs of the authors: O.S. 0000-0002-5557-6627; N.B. 0000-0002-6845-9550; N.D.K. 0000-0002-7558-6654; S.Y. 0000-0002-08858445; H.D. 0000-0002-7145-4769; E.K. 0000-0001-9620-9949; P.D. 0000-0002-8388-7166.

This study was presented as oral presentation at the $13^{\text {th }}$ National Emergency Medicine Congress, $4^{\text {th }}$ Intercontinental Emergency Medicine Congress, $4^{\text {th }}$ International Critical Care and Emergency Medicine Congress.

Corresponding Author: Omer Salt e-mail: dromersalt@gmail.com

Received: 19.11.2017 • Accepted: 29.01.2018

(c) Copyright 2018 by Emergency Physicians Association of Turkey - Available online at www.eajem.com

DOI: 10.5152/eajem.2018.30922 
the early phase (first $3 \mathrm{~h}$ ) of ischemic CVD (6). Intravenous (iv) t-PA administration was approved by the Food and Drug Administration in 1996 and was considered as the most promising treatment method in the first $3 \mathrm{~h}$ of ischemic CVD in $2012(3,7)$. Although it has clinically better results, iv t-PA therapy has a potential risk for intracerebral hemorrhage (3). Thrombolytic therapy is also frequently used by emergency physicians because patients are usually admitted to the emergency departments (EDs) in the early stage of CVD. However, owing to the risk of intracerebral hemorrhage, emergency physicians are often hesitant to apply this treatment.

Magnetic resonance imaging (MRI) shows the brain tissue better than computed tomography (CT) in patients admitted to the ED with clinical suspicion of CVD (6). It has also been reported that MRI with diffusion-weighted images and perfusion sequences may be helpful in identifying patients who will receive more benefit from t-PA therapy (8).

Table 1. Demographic characteristics of the patients included in the study

\begin{tabular}{|c|c|}
\hline Characteristics & n (\%) \\
\hline \multicolumn{2}{|l|}{ Gender } \\
\hline Male & $30(46.2)$ \\
\hline Female & $35(53.8)$ \\
\hline \multicolumn{2}{|l|}{ Comorbid disease } \\
\hline DM & $16(24.6)$ \\
\hline $\mathrm{HT}$ & $37(56.9)$ \\
\hline $\mathrm{CAD} / \mathrm{HF}$ & $20(30.6)$ \\
\hline CVD & $6(9.2)$ \\
\hline $\mathrm{AF}$ & $10(15.4)$ \\
\hline Smoking & $17(26.2)$ \\
\hline Carotid stenosis & $2(3.1)$ \\
\hline COPD & $5(7.7)$ \\
\hline CKF & $2(3.1)$ \\
\hline \multicolumn{2}{|l|}{ Antiplatelet agent use } \\
\hline No & $37(56.9)$ \\
\hline Aspirin & $20(30.8)$ \\
\hline Clopidogrel & $5(7.7)$ \\
\hline Coumadin & $1(1.5)$ \\
\hline Aspirin + clopidogrel & $2(3.1)$ \\
\hline \multicolumn{2}{|l|}{ GCS } \\
\hline$<12$ & $16(24.6)$ \\
\hline 13 & $12(18.5)$ \\
\hline 14 & $21(32.3)$ \\
\hline 15 & $16(24.6)$ \\
\hline
\end{tabular}

DM: diabetes mellitus; HT: hypertension; CAD: coronary artery disease; HF: heart failure; CVD: cerebrovascular disease; AF: atrial fibrillation; COPD: chronic obstructive pulmonary disease; CKF: chronical kidney failure; GCS: Glasgow Coma Scale
The aim of the present study was to determine the demographic characteristics, localization, imaging findings, National Institutes of Health Stroke Scale (NIHSS) scores, and complications of patients who received iv t-PA due to early period of ischemic CVD during the 6-year period in a tertiary level ED of a university hospital.

\section{Materials and Methods}

The present study was retrospectively performed in 65 patients aged $\geq 18$ years and who underwent iv t-PA with a diagnosis of ischemic CVD in a tertiary level ED of a university hospital for 6 years. The local ethics committee (Erciyes University Ethical Committee of Clinical Researches, Date: 21.03.2014, Decision Number: 2014/172) approved the study. Patients who received iv t-PA for urgent septicemia during the last 6 years with the help of the hospital registration system were identified.

Inclusion criteria for patients with ischemic stroke who had been able to acquire t-PA remedy within $4.5 \mathrm{~h}$ after the disease onset were as follows: (1) diagnosis of acute ischemic stroke, (2) measurable neurological deficits, and (3) symptom onset within 3-4.5 h before remedy. Exclusion criteria included (1) blood pressure that cannot be lowered safely to $<185 / 110 \mathrm{mmHg}$ with antihypertensive agents; (2) history of intracranial hemorrhage (this does not include cerebral microhemorrhages); (3) platelets $<100,000$, international

Table 2. Cranial CT and diffusion MRI findings of the patients

\begin{tabular}{|l|c|}
\hline Finding & $\mathbf{n}(\%)$ \\
\hline Cranial CT & \\
\hline Not performed & $0(0)$ \\
\hline No acute change & $51(78.5)$ \\
\hline Cerebral edema & $2(3.1)$ \\
\hline Hypodense area & $12(18.5)$ \\
\hline Diffusion MRI & \\
\hline Not performed & $27(41.5)$ \\
\hline No acute change & $2(3.1)$ \\
\hline Restricted diffusion on bilateral mesencephalon & $1(1.5)$ \\
\hline Restricted diffusion on right frontoparietal region & $2(3.1)$ \\
\hline Restricted diffusion on right MCA & $8(12.3)$ \\
\hline Restricted diffusion on right parietal region & $4(6.2)$ \\
\hline Restricted diffusion on right parietotemporal region & $1(1.5)$ \\
\hline Restricted diffusion on left basal ganglia & $3(4.6)$ \\
\hline Restricted diffusion on left side of brain stem & $2(3.1)$ \\
\hline Restricted diffusion on left capsula interna & $1(1.5)$ \\
\hline Restricted diffusion on left MCA & $7(10.8)$ \\
\hline Restricted diffusion on left parietal region & $3(4.6)$ \\
\hline Restricted diffusion on left parietotemporal region & $3(4.6)$ \\
\hline Restricted diffusion on left temporal region & $1(1.5)$ \\
\hline & \\
\hline computed tomogaphy; (1) & \\
\hline (1) & \\
\hline
\end{tabular}

CT: computed tomography; MCA: middle cerebral artery; MRI: magnetic resonance imaging. 
normalized ratio>1.7, activated partial thromboplastin time $($ aPTT $)>40 \mathrm{~s}$, or prothrombin time $>15 \mathrm{~s}$; (4) use of therapeutic or prophylactic dose low-molecular-weight heparin within $24 \mathrm{~h}$ or any

Table 3. Time of admission, complications, and outcome of thrombolytic therapy

\begin{tabular}{|l|c|}
\hline & $\mathbf{n}(\%)$ \\
\hline Time of admission & \\
\hline $00: 00-08: 00$ & $15(23.1)$ \\
\hline $08: 00-16: 00$ & $20(30.8)$ \\
\hline $16: 00-00: 00$ & $30(46.2)$ \\
\hline Complication & \\
\hline Exist & $11(16.9)$ \\
\hline Not exist & $54(83.1)$ \\
\hline Outcome & \\
\hline Exitus in ED & $1(1.5)$ \\
\hline Exitus in ICU & $20(30.8)$ \\
\hline Discharged from ICU & $44(67.7)$ \\
\hline
\end{tabular}

$E D$ : emergency department; ICU: intensive care unit unfractionated heparin use associated with an elevated aPTT; (5) use of direct thrombin inhibitors (dabigatran) or factor Xa inhibitors (rivaroxaban, apixaban, and edoxaban) within $48 \mathrm{~h}$; (6) patients with a structural gastrointestinal (GI) malignancy or Gl bleeding within 21 days; (7) ischemic stroke and symptoms consistent with infective endocarditis; (8) known or suspected aortic dissection; (9) intracranial or intraspinal surgery within the last 3 months; and (10) intra-axial intracranial neoplasm (extra-axial intracranial neoplasm is not a contraindication).

Cranial CT and diffusion MRI were used for diagnostic imaging of the patients. Patient files and t-PA application forms were used to access patient information.

Demographic data such as age, sex, smoking, use of anticoagulation and/or antiaggregant drugs, and chronic illness were obtained by examining the medical records of the patients. The baseline Glasgow Coma Scale (GCS), NIHSS, start time of the event, time of admission to the hospital, blood parameters, application time of $\mathrm{t}-\mathrm{PA}$, presence or absence of secondary hemorrhagic complications due to $\mathrm{t}-\mathrm{PA}$, and prognosis of the patients were recorded on the study form. Mortality rates due to intracranial hemorrhage during hospital stay of the patient after t-PA admission were also recorded on the study form.

Table 4. Relationship among t-PA initiation time, NIHSS score, age, hemorrhagic complications, and patients' outcome

\begin{tabular}{|l|c|c|c|c|c|c|}
\hline \multirow{2}{*}{} & \multicolumn{3}{|c|}{ Complication } & \multicolumn{3}{c|}{ Outcome } \\
\cline { 2 - 7 } & Exist & Not exist & p & Exitus & Discharged & p \\
\hline Initiation time of t-PA treatment (min) & $133.1 \pm 52.6$ & $130 \pm 40$ & 0.821 & $136.1 \pm 48.5$ & $127.8 \pm 38.7$ & 0.458 \\
\hline NIHSS score & $14 \pm 4$ & $10.9 \pm 4.2$ & 0.025 & $14.1 \pm 4.5$ & $10.1 \pm 3.6$ & $<0.001$ \\
\hline Age (year) & $66 \pm 15.6$ & $66.3 \pm 12.3$ & 0.958 & $69 \pm 10.2$ & $64.9 \pm 13.8$ & 0.241 \\
\hline
\end{tabular}

NIHSS: National Institutes of Health Stroke Scale; t-PA: tissue plasminogen activator

Table 5. Relationship among time of administration of t-PA, additional drug use, smoking, and complication or mortality

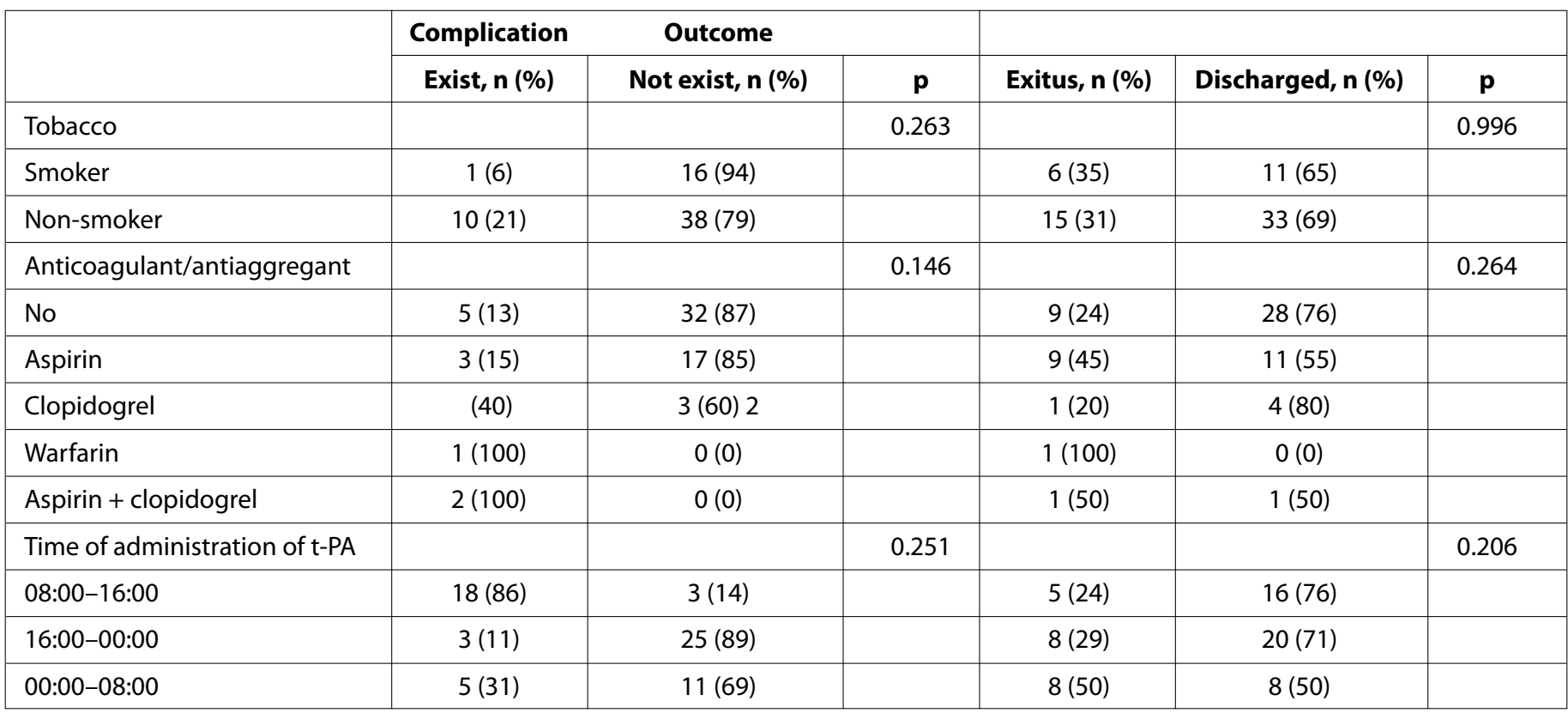

t-PA: tissue plasminogen activator 


\section{Statistical analysis}

The duration of t-PA therapy applied to the patient, time of admission, NIHSS scores, age of the patients, and relationship between intracerebral hemorrhage complication and mortality were assessed by independent t-test. The chi-square test was used to evaluate the relationship among the radiological findings of patients, time interval of t-PA treatment applied to the patient, anticoagulant/antiaggregant agent, and cigarette use.

\section{Results}

Sixty-five patients who met the study criteria were included in the study. The mean age of the patients was 66.2 years (min-max: 24-79 years), and $46.2 \%(n=30)$ of the patients were men and $53.8 \%(n: 35)$ of the patients were women. Table 1 shows the demographic data such as comorbid diseases, anticoagulant/antiaggregant drug use, and GCS scores.

Cranial CT scan was performed in all of the patients, and $78.5 \%$ of the patients had no acute pathological findings. It was observed that diffusion MRI was not performed in $41.5 \%$ of the patients, and middle cerebral artery infarction was detected in $23.1 \%$ of the patients with diffusion MRI performed. Table 2 shows the cranial imaging results of the patients.

When the times in which patients receive thrombolytic therapy are examined, the highest rate was found with $46.2 \%$, in the period of 16:00-00:00. The average time interval between event occurrence and hospital arrival was $70 \pm 39 \mathrm{~min}$, the average time interval between the time of arrival to the hospital and the time of application of t-PA treatment was $59 \pm 24 \mathrm{~min}$, and the average time interval between the time of occurrence of the event and the time of application of t-PA was $130 \pm 41 \mathrm{~min}$.

Hemorrhagic complications were detected in $16.9 \%$ of the patients after treatment, and all of these complications were intracranial hemorrhage. On examination of the patients' outcome, $1.5 \%(n=1)$ of the patients died in the ED, and 20 of 21) patients died in the intensive care unit. The mortality rate of the patients who received t-PA therapy in the ED was lower than that in the other departments where patients transferred. However, we hypothesized that it would be related to the short duration time of the patients in the ED compared with other departments. Hemorrhagic complications were present after t-PA admission in 6 out of a total of 21 patients who died. In order to evaluate the most common administration time of t-PA in the ED, we have evaluated three shifts. Further, it has been found that it is most commonly used in the period between 16:00 and 0:00 h. Table 3 shows the patients' time for t-PA administration, complications, and outcome patterns.

The baseline NIHSS and GCS scores were assessed to evaluate the neurological status of the patients and were found to be $11.4 \pm 4.3$ and $13 \pm 2.1$ points, respectively.

While no significant relationship was found between the initiation time of t-PA treatment and complication development, a significant correlation was found between high NIHSS score and complication development and mortality. Table 4 shows these values.
No significant association was found between smoking, anticoagulant/ antiaggregant drug use, time to administration of t-PA treatment, and complication development or mortality. Table 5 shows these findings.

\section{Discussion}

It was found that $23 \%(n=7)$ of male patients and $40 \%(n=14)$ of female patients who were included in the study died. According to the records of the Ministry of Health of Turkey regarding death rates due to CVD, $15.5 \%$ were men and $15.7 \%$ were women. This rate increases to $20.8 \%$ in men and $20.2 \%$ in women over 60 years old in urban areas (5). In our study, mortality rates were found to be higher $(32.3 \%)$ than country rates. We think that the high mortality rate is due to the fact that our hospital is a university hospital, and we usually treat patients with high comorbidity. Although the same t-PA protocol was applied to all of the patients, the mortality rates in the ED were lower than those in the other departments. We think that it could be related to the duration time of the patients because the duration time of the patients in the ED was short. Most of them were transferred to the other departments after admission of iv t-PA.

There was no significant relationship between the initiation time of t-PA treatment and the complication of intracerebral hemorrhage in our study. This result is consistent with previous studies showing the efficacy and safety of initiation of t-PA therapy within the first $4.5 \mathrm{~h}$ (9). While it is stated in the literature that there is a significant relationship between the time of initiation of treatment and mortality (10), it has been observed that the initiation of treatment in any period within the first $4.5 \mathrm{~h}$ in our study does not affect mortality (11). This suggests that starting treatment at any time within the first $4.5 \mathrm{~h}$ will not affect mortality.

There was no significant association between smoking, anticoagulant/ antiaggregant drug use, time to administration of t-PA treatment, and complication development or mortality. We believe that these results are satisfactory for t-PA use, since it shows that patients with these clinical conditions are not under increased risk of intracranial complications, and t-PA could be used for such patients safely.

In the literature, it was stated that an NIHSS score of $\geq 8$ at the time of admission indicates increased risk of intracerebral hemorrhage and mortality (3). In our study, the NIHSS scores of all patients who developed complications or died were $\geq 8$. This suggests that the high NIHSS score of the patient at the time of admission would alert the emergency physician of complications and mortality.

It has been reported in literature that high blood glucose levels are associated with increased intracerebral hemorrhage risk in patients receiving t-PA (3). A previous study reported that a pretreatment blood glucose level of $>200 \mathrm{mg} / \mathrm{dL}$ is a high risk factor for intracerebral hemorrhage alone (12). However, in our study, the average blood glucose level of patients with complications was $157 \mathrm{mg} / \mathrm{dL}$. This suggests that high blood glucose level alone is not responsible in terms of risk of developing intracerebral hemorrhage in patients receiving t-PA due to CVD.

It has been determined that the only factor that poses an independent risk for both parenchymal hematomas and intracerebral hemorrhage 
is age (12). Despite the risk of intracerebral hemorrhage, there are studies showing the benefit of iv t-PA in elderly patients (13-16). In our study, the mean age of the patients with complications was $66.9 \pm 1.5$ years, whereas the mean age of the patients without complications was $66.3 \pm 1.2$ years. This finding was not consistent with the literature, and there was no significant relationship between age and complication ( $p>0.05$ ). This suggests that other comorbid conditions, in addition to age, are also related to the development of complications. There was no significant correlation between age and mortality ( $p>0.05)$, which was consistent with the literature. For this reason, we believe that when the decision to use iv t-PA is made, especially in elderly patients, not only the risks but also the benefits must be kept in mind.

\section{Study limitations}

The major limitation of the present study is that it is performed in a single center. In addition, the study population was limited, and studies conducted with larger populations are needed. Another limitation of the present study is that the duration time of admission to the ED and t-PA treatment starting time of all of the patients are not the same.

\section{Conclusion}

In our study, it has been seen that the high NIHSS score at the time of admission increases both the risk of intracerebral hemorrhagic complication and mortality. While a correlation between the age of the elderly and the development of intracerebral hemorrhagic complications was reported in literature reviews, there was no significant relationship found in the present study. We hypothesize that iv t-PA treatment gives successful results despite the complications in emergency patients with CVD, and emergency physicians should be more courageous in their application especially in elderly patients.

Ethics Committee Approval: Ethics committee approval was received for this study from the ethics committee of Erciyes University (Date: 21.03.2014, Decision number: 2014/172).

Informed Consent: Written informed consent was not obtained from patients. Because this study was conducted retrospectively and "Patients" are not included in our study, so "patient consent" is not available.

Peer-review: Externally peer-reviewed.

Author Contributions: Concept - O.S.; Design - O.S., N.B.; Supervision P.D., H.D., E.K.; Resources - O.S., S.Y.; Materials - E.K.; Data Collection and/or Processing - O.S., N.B., S.Y.; Analysis and/or Interpretation - O.S., N.D.K., S.Y., E.K, P.D.; Literature Search - O.S., N.B., S.Y., H.D., E.K.; Writing Manuscript - O.S., N.B., S.Y.; Critical Review - P.D., E.K., H.D.; Other - O.S., N.B.

Conflict of Interest: The authors have no conflict of interest to declare.
Financial Disclosure: The authors declared that this study has received no financial support.

\section{References}

1. Zhang PL, Wang $\mathrm{YX}$, Chen $\mathrm{Y}$, Zhang $\mathrm{CH}, \mathrm{LiCH}$, Dong Z, et al. Use of intravenous thrombolytic therapy in acute ischemic stroke patients: evaluation of clinical outcomes. Cell Biochem Biophys. 2015; 72: 11-7. [CrossRef]

2. Coskun F, Kutluk K, Karcioglu O. The prognostic value of the barthel index of the NIH stroke scale in stroke patients. Eurasian J Emerg Med. 2003; 2: 30-4.

3. Sezer E. Akut iskemik inmede intra-venöz trombolitik tedaviye bağlı gelişen intraserebral hemorajide risk faktörlerinin saptanması. Tıpta uzmanlık tezi. Eskişehir. 2014.

4. Feigin VL. Stroke epidemiology in the developing world. Lancet. 2005; 365: 2160-1. [CrossRef]

5. Türkiye hastalık yükü Çalışması 2004- (Ed) Ünivar N, Mollahaliloglu S, Yardim N. Ankara 2006, RSHMB Hıfzısıhha Mektebi Müdürlüğü, Sağlık Bakanlığı, Aydogdu Ofset Matbaacılık, 2007.pp.24-41.

6. Yoo SH, Kwon SU, Lee DH, Kim SJ, Kim JS, Kang DW. Comparison between MRI screening and CT-plus-MRI screening for thrombolysis within $3 \mathrm{~h}$ of ischemic stroke. J Neurol Sci. 2010; 294: 119-23. [CrossRef]

7. Hanselman Carol J. Timing of tissue plasminogen activator for acute ischemic stroke: Outcomes-based recommendations for practice. J Neurosci Nurs. 2014; 46: 314-20. [CrossRef]

8. Köhrmann M, Juttler E, Fiebach JB, Huttner HB, Siebert S, Schwark C, et al. MRI versus CT-based thrombolysis treatment within and beyond the $3 \mathrm{~h}$ time window after stroke onset: a cohort study. Lancet Neurol. 2006; 5: 661-7. [CrossRef]

9. Hacke W, Kaste W, Bluhmki E, Brozman M, Davalos A, Guidetti D, et al. Thrombolysis with alteplase 3 to 4.5 hours after acute ischemic stroke. N Engl J Med. 2008; 359: 1317-29. [CrossRef]

10. Kutluk K, Kaya D, Afsar N, Arsava EM, Ozturk V, Uzuner N, et al. Analyses of the Turkish National Intravenous Thrombolysis Registry. J Stroke Cerebrovasc Dis. 2016; 25: 1041-7. [CrossRef]

11. Kaplan DM. Pathophysiology, Diagnosis and management of stroke. Barnet HM, Mohr JP, Stein BM, Yatsu FM, editors. London: Churchill Livingstone; 1996.p.54-56.

12. Khatri Pooja, Wechsler Lawrence R, Broderick Joseph P. Intracranial hemorrhage associated with revascularization therapies. Stroke. 2007; 38: 431-40. [CrossRef]

13. Tanne D, Kasner SE, Demchuk AM, Koren-Morag N, Hanson S, Grond $M$, et al. Markers of increased risk of intracerebral hemorrhage after intravenous recombinant tissue plasminogen activator therapy for acute ischemic stroke in clinical practice the multicenter rt-PA acute stroke survey. Circulation. 2002; 105: 1679-85. [CrossRef]

14. Demchuk AM, Morgenstern MB, Krieger DW, Chi TL, Hu W, Wein TH, et al. Serum glucose level and diabetes predict tissue plasminogen activatorrelated intracerebral hemorrhage in acute ischemic stroke. Stroke. 1999; 30: 34-9. [CrossRef]

15. Sylaja PN, Cote R, Buchan AM, Hill MD. Thrombolysis for acute ischemic stroke patients aged 80 years and older: Canadian Alteplase for Stroke Effectiveness Study. J Neurol Neurosurg Psychiatry. 2006; 77: 826-9. [CrossRef]

16. Berrouschot J, Röther J, Glahn J, Kucinski T, Fiehler J, Thomalla G. Outcome and severe hemorrhagic complications of intravenous thrombolysis with tissue plasminogen activator in very old ( $\geq 80$ years) stroke patients. Stroke. 2005; 36: 2421-5.[CrossRef] 